\title{
Don't Throw the Baby Out with the Bathwater-Sample Collection and Processing Issues Associated with Particulate Solids in Stormwater
}

\author{
Robert Pitt, ${ }^{1}$ Shirley E. Clark, ${ }^{2}$ Vijay Kumar Eppakayala ${ }^{3}$ and Redahegn Sileshi ${ }^{4}$ \\ ${ }^{1}$ University of Alabama, Tuscaloosa, Alabama; ${ }^{2}$ Penn State Harrisburg, Middletown, Pennsylvania; ${ }^{3}$ Hoskin Ryan Consultants, Phoenix, \\ Arizona; ${ }^{4}$ University of North Georgia, Gainesville, Georgia.
}

\begin{abstract}
Particulate solids are the most common constituent examined during stormwater monitoring projects. They have also been used as the basis of many regulatory programs, mostly as a surrogate for particulate bound pollutants, such as metals and nutrients. There is controversy concerning older total suspended solids values compared to newer data observations (such as when comparing total suspended solids, TSS, values with suspended sediment concentration, SSC), especially when used in conjunction with the particle size distributions (PSDs). As part of this controversy, some have advocated not using the earlier TSS data as being unreliable.
\end{abstract}

Some commonly used sampling and analytical procedures do not represent the complete range of particle sizes present in the water being sampled. If the PSD is mismatched with the particulate solids information, incorrect calculations will lead to misleading stormwater control calculations. Most stormwater controls preferentially remove large particles (faster settling in sedimentation devices, easier to trap in filtering facilities, easier to remove by conventional street cleaners). Therefore, if SSC PSDs are incorrectly paired with TSS concentration data, more of the TSS load would be calculated to be removed by stormwater controls than actually occurs. It is therefore important that the correct particle size distributions be matched with the particulate solids concentrations when conducting these modeling calculations for the most accurate performance and characterization predictions.

This paper presents the results of several stormwater monitoring studies that have examined alternative sample collection and laboratory analyses options focusing on stormwater particulate solids and particle size distributions. Recommendations are made to assist in the selection of the most appropriate stormwater sampling and processing methods based on actual monitoring results and mass balance calculations.

\section{Particulate Solids Collection and Analy- ses Options}

The analyses of particle size distributions of stormwater runoff along with associations of different pollutants with the different particle sizes plays a key role in understanding the pollutant characteristics of a specific site concerning the contaminant's fate and treatability. Several studies have been conducted to examine the particle size distributions originating from different land use settings. Pitt et al. (1995) studied particle size analyses of 121 stormwater inlets from three different states in the United States. Median particle sizes ranged from $0.6 \mu \mathrm{m}$ to $38 \mu \mathrm{m}$. In a study conducted by House et al. (1993), particle sizes were studied from stormwater routed through the Monroe St. detention pond in Madison, Wisconsin and the observed median particle sizes ranged from $2 \mu \mathrm{m}$ to $26 \mu \mathrm{m}$ for a variety of storms. Li et al. (2006) studied particle size distributions originating from highway runoff and showed that $97 \%$ of the particles were $<30 \mu \mathrm{m}$ and nearly $30 \%$ to $60 \%$ of the particle mass is found in particles $<50 \mu \mathrm{m}$.

There are two separate issues associated with obtaining particulate solids information:

- sampling to obtain representative water samples; and

- laboratory processing to represent all particles.

Some options result in losses of large particles, while others produce a bias with more large particles in the sample. The combination of sampling and analytical methods used therefore affects the particulate solids characteristics presented for the water sample.

Pitt, Robert E., Shirley E. Clark, Vijay Kumar Eppakayala and Redahegn Sileshi. 2017. Don't Throw the Baby Out with the Bathwater-Sample Collection and Processing Issues Associated with Particulate Solids in Stormwater. Journal of Water Management Modeling 25:C416.

https://doi.org/10.14796/JWMM.C416 @ CHI 2017. www.chijournal.org ISSN 2292-6062. 


\subsection{Sampling Effects on Particle Size Distribu- tions}

Andral et al. (1999) studied particulates in runoff from the A9 motorway in France. They found the median particle size to be $\sim 15 \mu \mathrm{m}(\mathrm{v} / \mathrm{v})$. The densities of the particulates were all in a relatively narrow range $\left(2.4 \mathrm{~g} / \mathrm{cm}^{3}\right.$ to $\left.2.9 \mathrm{~g} / \mathrm{cm}^{3}\right)$ for all events and size ranges, reflecting the relative homogeneity of the roadway runoff particulates. The median settling velocities were about $2 \mathrm{~m} / \mathrm{h}$ and $10 \mathrm{~m} / \mathrm{h}$ for particles $<50 \mu \mathrm{m}$ and $50 \mu \mathrm{m}$ to $100 \mu \mathrm{m}$ respectively. Later, Kim and Sansalone (2008) conducted an extensive review of stormwater PSD data for comparison with data they collected. They found a very wide size range of particulates in stormwater that caused significant challenges in sampling and analyses. They found that misrepresentation of this data can be due to long holding times before analyses and not representing the complete sample, especially for particles $>75 \mu \mathrm{m}$ that are commonly underreported.

As described by Burton and Pitt (2002), some sampling problems are associated with stratified flows. Sampler intakes placed on the bottom of pipes or channels may collect more bedload than represented in well mixed samples. The bedload is comprised of particulates having a greater settling velocity than other stormwater particulates. Another potential sampler problem is associated with the automatic sampler tube sample velocity. The sampler tube water velocity may not be able to transport large particles to the elevated sample bottles in the automatic sampler. These are two opposite problems that seldom cancel each other out nicely. These errors can be quantified as part of complete mass balance analyses associated with the evaluation stormwater controls.

Typical sample lines are Teflon lined polyethylene and are $10 \mathrm{~mm}$ in diameter. The water velocity in automatic sampler lines is $\sim 100 \mathrm{~cm} / \mathrm{s}$, enabling most of the particulates to be transported to the sample containers. Table 1 shows the particle sizes that would be lost in vertical sampling lines at this pumping rate for the typical stormwater particulate specific gravities of $1.5 \mathrm{~g} / \mathrm{cm}^{3}$ to $2.7 \mathrm{~g} / \mathrm{cm}^{3}$.

Table 1 Losses of particles in automatic sampler tubing $(100 \mathrm{~cm} / \mathrm{s}$ velocity).

\begin{tabular}{lcc}
\hline & Critical settling rate $(\mathrm{cm} / \mathrm{s})$ & $\begin{array}{c}\text { Size range } \\
\left(\mu \mathrm{m}, \text { for } \rho=1.5 \mathrm{~g} / \mathrm{cm}^{3} \text { to } 2.7 \mathrm{~g} / \mathrm{cm}^{3}\right)\end{array}$ \\
\hline $100 \%$ loss & 100 & $8000-25000$ \\
$50 \%$ loss & 50 & $3000-10000$ \\
$25 \%$ loss & 25 & $1500-3000$ \\
$10 \%$ loss & 10 & $350-900$ \\
$1 \%$ loss & 1 & $100-200$ \\
\hline
\end{tabular}

Burton and Pitt (2002)

A water velocity of $100 \mathrm{~cm} / \mathrm{s}(\sim 3 \mathrm{ft} / \mathrm{s})$ in the sampler line would result in very little loss of typical stormwater particles. Particles of $8 \mathrm{~mm}$ to $25 \mathrm{~mm}$ would not be lifted in the sample line at all at this velocity, but these sized particles would obviously not fit through the openings of the intake or even fit in $10 \mathrm{~mm}$ sample lines. They are also not present in stormwater, but may be a component of bedload in a stream, or gravel in the bottom of a storm drain pipe, requiring special sampling procedures. Relatively few particles larger than several hundred micrometers occur in stormwater and these should only have a loss rate of $~ 10 \%$ to $25 \%$ at the most. Most particles in stormwater are between $1 \mu \mathrm{m}$ and $100 \mu \mathrm{m}$ in diameter and have a density of between $1.5 \mathrm{~g} / \mathrm{cm}^{3}$ and $2.7 \mathrm{~g} / \mathrm{cm}^{3}$, although some can be several $\mathrm{mm}$ in diameter. ASTM (2014) in method D 4411 recommends that the sample velocity in the sampler line be at least 17 times the fall rate of the largest particle of interest. As an example, for the $100 \mathrm{~cm} / \mathrm{s}$ example above, the ASTM recommended critical fall rate would be $\sim 6 \mathrm{~cm} / \mathrm{s}$, enabling a particle of several hundred micrometers in diameter to be sampled with a loss rate of $<10 \%$. This is likely adequate for most stormwater sampling needs.

When monitoring the performance of stormwater control devices, influent and effluent samples are usually collected and the difference in observed mass loads can be used to calculate the amount of pollutants trapped in the device. If the amount of material captured can be directly measured (such as removing and weighing the material trapped in a sump) for the same study period, the control effectiveness can be directly measured (and any differences can be expected to be caused by sampling issues). Table 2 summarizes the results of a 12 month monitoring program of a hydrodynamic separator at a public works yard in Madison, Wisconsin conducted by the U.S. Geological Survey (USGS) and the Wisconsin Department of Natural Resources (WI DNR).

Table 2 Results of verification monitoring of a hydrodynamic separator (Madison, WI).

\begin{tabular}{ll}
\hline Sampled solids load in & $1623 \mathrm{~kg}$ \\
Sampled solids load out & $1218 \mathrm{~kg}$ \\
Trapped by difference & $405 \mathrm{~kg}$ (25\% removal) \\
Actual trapped total sediment by direct measurement & $536 \mathrm{~kg}$ (33\% actual removal) \\
Fraction total solids not captured by automatic samplers & $8 \%$ (131 kg missed by sampler, out of \\
& $1623 \mathrm{~kg}$ in sampler) \\
\hline
\end{tabular}

It is assumed that the device preferentially removed the larger particles (confirmed by particle size analyses of the captured material) while the effluent samples did not suffer any mass loss. Therefore, the missed $131 \mathrm{~kg}$ material (the extra amount of material in the device sump compared to the difference in the monitored loads from the sampling equipment) was associated with the influent sampler not capturing the largest particles. When the performance calculations were adjusted to account for this non-monitored material, the device performance increased from $25 \%$ to $33 \%$ particulate solids removal.

During a series of street cleaning performance monitoring studies, the USGS and the WI DNR supplemented the automatic water samplers with bedload trap samplers, as illustrated in Figure 1. As shown in the photos, three bedload traps were located in the drain pipe after the automatic sampler. The first trap was usually full, while the middle trap was partially full, and the last 
one had little material, indicating that all of the bedload was captured in the traps. The bedload was measured and compared to the monitored stormwater particulate solids yields. The bedload was found to comprise about $4 \%$ of the total particulate discharges and was not represented in the automatic samplers during the project.
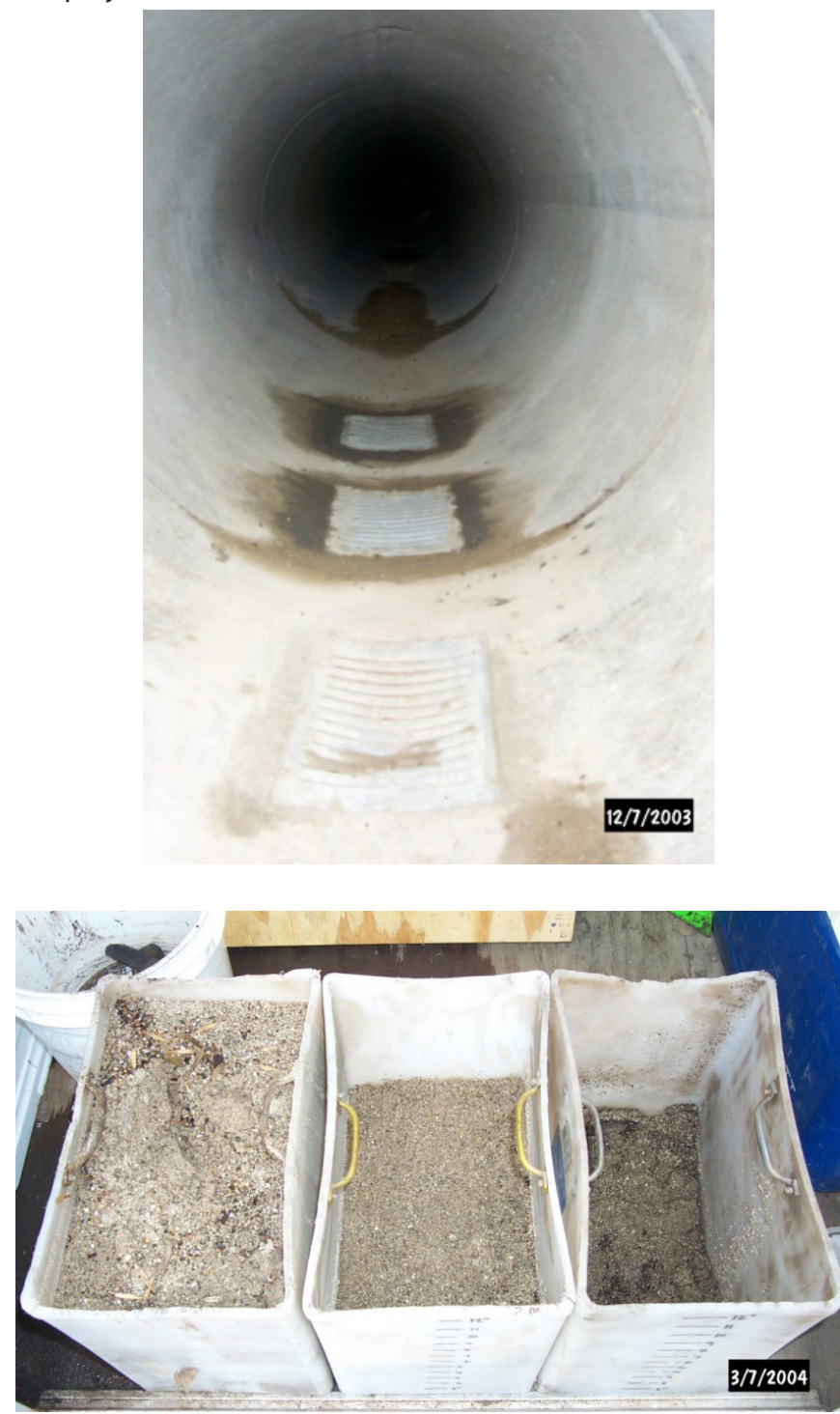

Figure 1 Series of bedload samplers used to supplement automatic water samplers (USGS and WI DNR data).

In another Madison, Wisconsin area monitoring project, the USGS and WI DNR collected influent samples at the Monroe St. wet detention pond using a combination of automatic water samplers and bedload samplers. The resulting particle size distributions for several multi-week sampling periods are shown in Figure 2 . Over this long period of sampling, $\sim 15 \%$ of the particles by mass (on average) were $>150 \mu \mathrm{m}$, with the largest particles $>\sim 2$ $\mathrm{mm}$, while the average median particle size was only $8 \mu \mathrm{m}$. These plots also show the typical variability of PSD at the same location during different sampling periods.

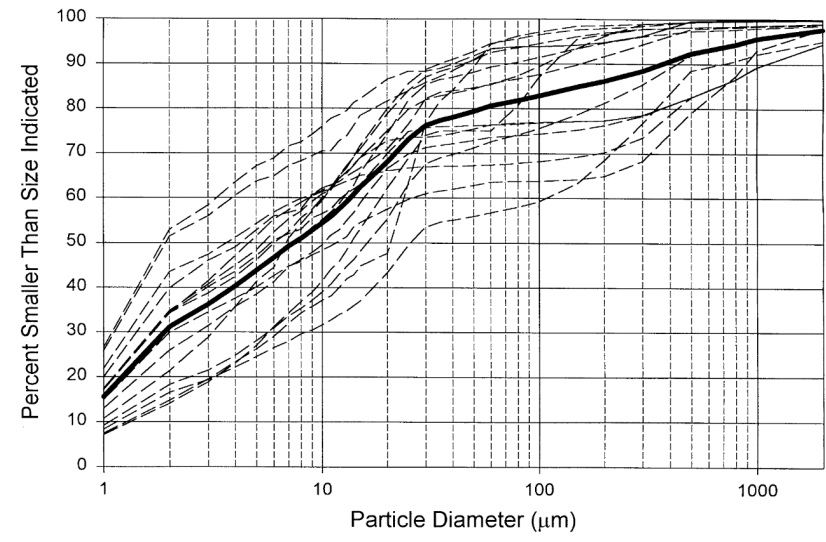

Figure 2 Particle size distributions at the inlet to the Monroe

St. wet detention pond from automatic water samplers and bedload samplers (USGS and WI DNR data).

Even though large particles of several hundred micrometers make up a small portion of stormwater particulates at outfalls, they can be visually obvious as bedload and near outfalls in receiving waters, as shown in Figure 3. This is a corrugated metal stormwater pipe with bedload and an accumulation of large particulates at a discharge location into a wet detention pond after several years of operation at a ski resort at Snowmass, Colorado. This outfall drains a several acre resort paved parking area having sand applications for traction control in the winter.

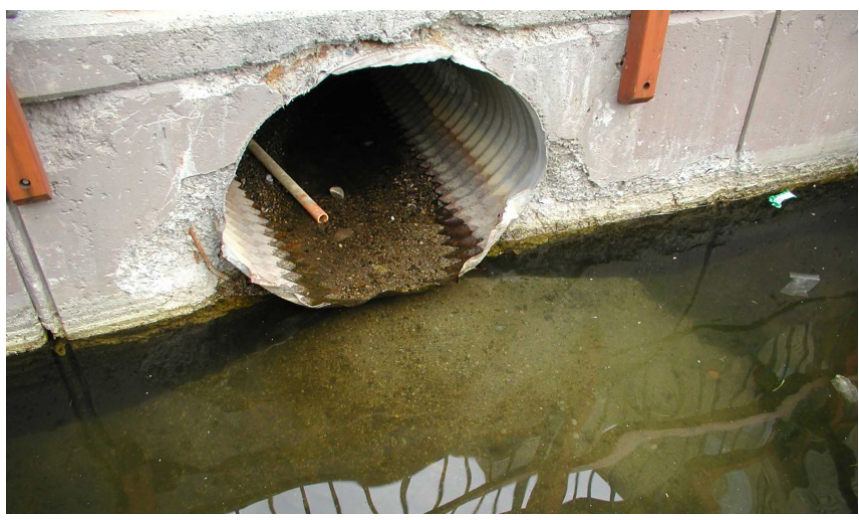

Figure 3 Large particles as bedload and accumulating near outfall in receiving water pond.

\subsection{Sampling Methods to Obtain Representative Particle Size Distributions in Stormwater Drainage Systems}

Automatic samplers can transport a wide range of stormwater particulates into the sampler bottles, with likely $25 \%$ under-representativeness associated with particles of several $\mathrm{mm}$, and less than $1 \%$ sampling errors of particles up to several hundred micrometers. However, it is apparent that samplers do not collect the largest particles well. This is likely due to poor placement of the sampler intake and the stratification of the large particulates in the flowing water. Large particles are at higher concentra- 
tions along the bottom of the pipe, with the largest making up a semi-permanent stationary bedload, and others slowly being transported along the bottom of the stormwater drain pipe. If the sampler intake is located on the bottom of the pipe, it may oversample these large particles. If located several inches off the pipe bottom, the intake may miss these larger particles.

Several sampling methods may be used to obtain the most representative samples, such as:

1. The use of bedload samplers can quantify the moving bedload material to supplement samples collected from automatic samplers. In this case, the sampler intake should be located several inches above the bottom of the pipe so the large material collected in the bedload samplers is not double counted.

2. A simple option to obtain representative stormwater samples is to create cascading and well mixed flow at the sampling location. This can provide a well mixed flow including moving bedload and no stratification. Figure 4 shows examples for gutter and pipe flow installations at cascading water installations.

3. The classical approach for collecting representative samples in stratified flows is to use a depth-integrated sampler. This is normally done in streams and other open channel flows with manual sampling. Figure 5 shows an automatic depth-integrated sampler (DIS) intake recently developed and tested by the USGS and the WI DNR. Selbig et al. (2016) monitored stormwater PSD using this newly developed depth-integrated stormwater sampler for 20 events at a commercial parking lot and during 19 events at a residential basin. The PSD data were successfully fitted to a Weibull distribution. This sampler resulted in much more reliable and repeatable data than information obtained using conventional automatic water samplers. They concluded that much more cost-effective stormwater sedimentation controls resulted when using this new data compared to historical information during modeling analyses. During these evaluations, this device resulted in superior representations of particulates in stormwater during a wide range of flow and concentration conditions. It is hoped that this unit will become commercially available for routine sampling.

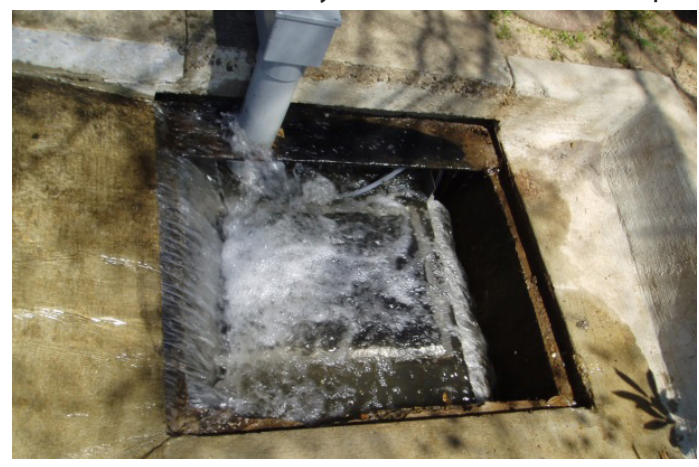

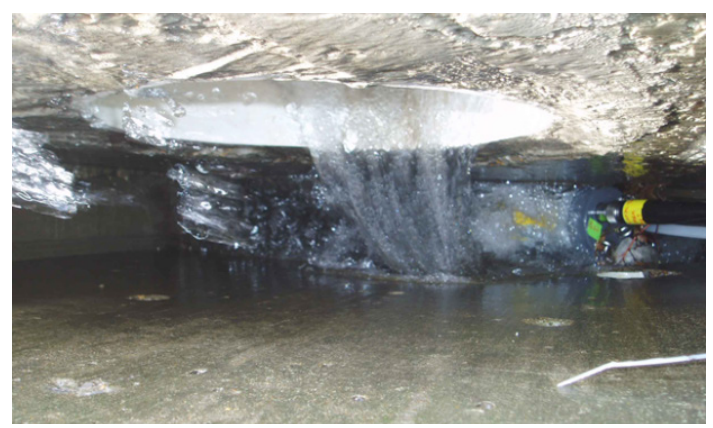

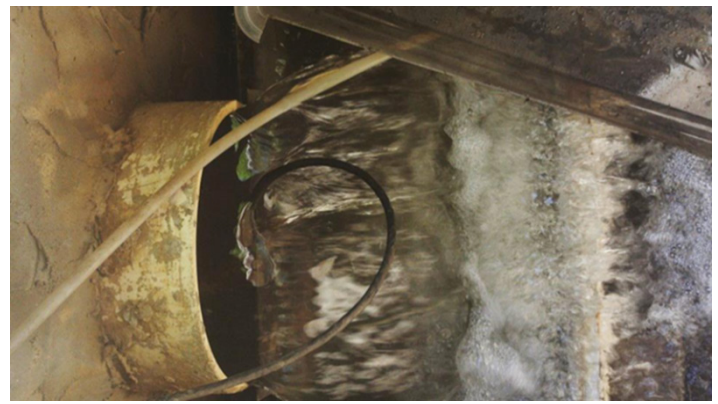

Figure 4 Sampler intakes located at well mixed cascading water locations.

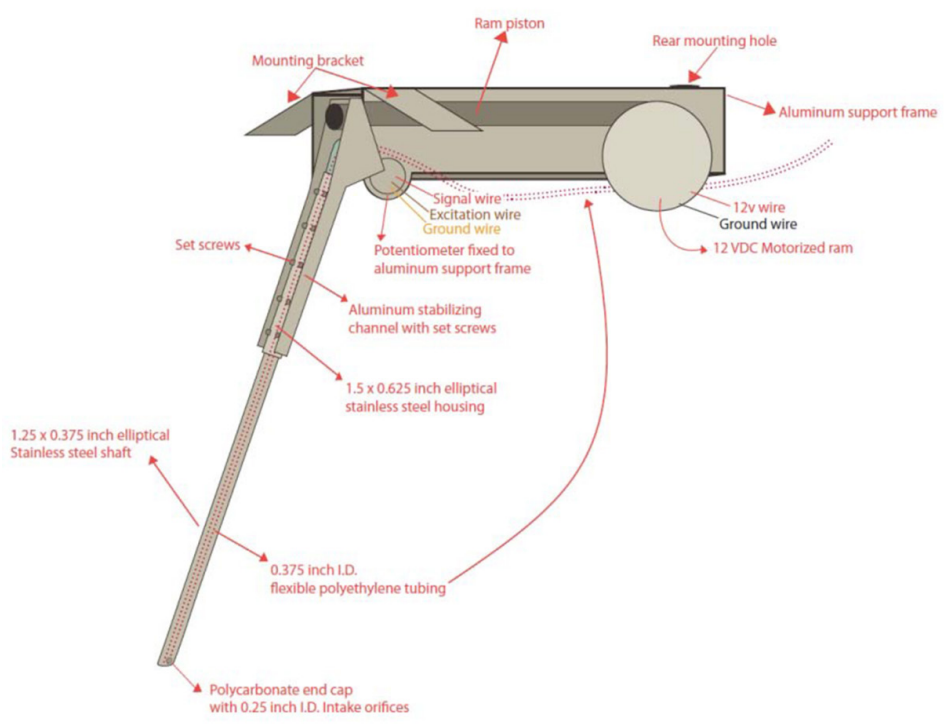

Figure 5 Depth integrated sampler (DIS) arm developed by the USGS and WI DNR for stormwater sampling.

\section{Laboratory Methods for TSS and SSC Determinations in Stormwater Samples}

As noted previously, the particle size distribution must be mated correctly with the sampling and analytical methods to make sense of the data. The main methods used to process samples (subsampling to obtain the known volume of sample portion for filtering) prior to particulate solids (those that are retained on a filter with a nominal filter pore size $\sim 0.45 \mu \mathrm{m}$ to $2 \mu \mathrm{m}$ ) analyses include: 
1. EPA TSS 160.2. This method involves shaking the sample bottle vigorously and then pouring into a graduated cylinder to obtain the $100 \mathrm{~mL}$ aliquot that is then filtered. This method is referred to as the shake and pour method.

2. Standard Methods TSS 2540D. This method uses a stir plate to form a vortex in the sample bottle and then using a wide bore pipette to withdraw the $100 \mathrm{~mL}$ aliquot by withdrawing the subsample at mid-depth in the sample bottle and midway between the bottle wall and the vortex. This method is referred to as the stir and pipette method.

3. ASTM SSC D3977-97B. This method does not split the sample using either of the above methods, but uses the entire sample which is poured from the original bottle. It is recommended to use the USGS/ Dekaport cone splitter (available from the Rickley Hydrological Company) to separate the sample into smaller volumes for different analyses.

The following discussion describes the sample processing we are using for SSC analyses. Figure 6 is the USGS/Dekaport cone splitter which is made of Teflon. As shown, the entire sample from the sample bottle is poured into the splitter. In order to prevent clogging of the splitter orifices, the sample can be poured through a coarse screen located above the splitter. Figure 7 is an example of the larger debris that was collected on a $1100 \mu \mathrm{m}$ fiberglass screen while splitting a $5 \mathrm{~L}$ sample. This larger material is also dried, weighed and analyzed.

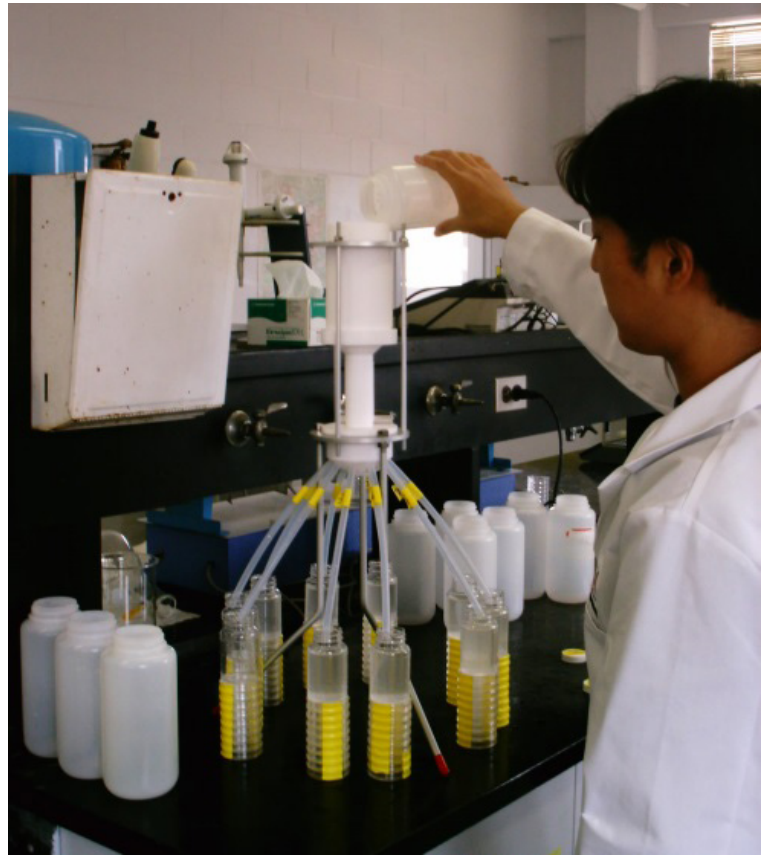

Figure 6 Stormwater sampling being split using a USGS/ Dekaport cone splitter.

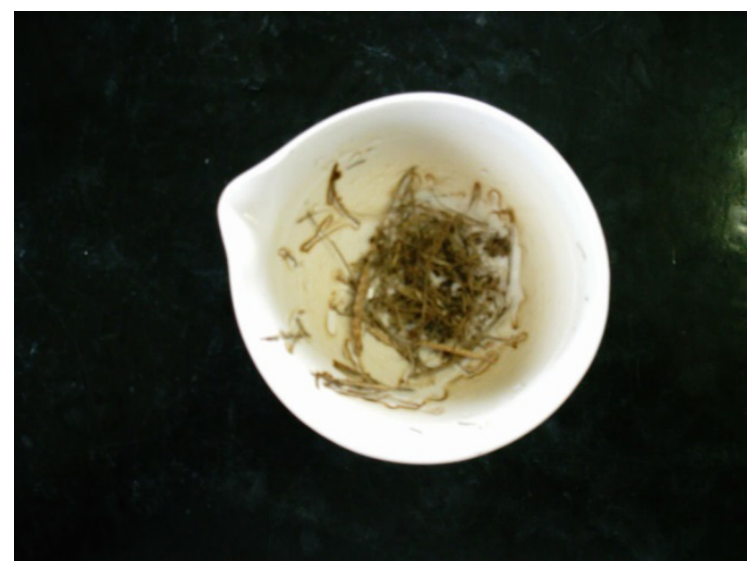

Figure 7 Screened material showing grass debris (from $5 \mathrm{~L}$ original sample).

The following summarizes our general procedure for particle size analyses of samples using the cone splitter, a Coulter Counter Multi-Sizer 3, and sieves. The Coulter Counter technology measures particles in fluids by quantifying the changes in electrical conductance as particles suspended in a conductive fluid passed through a small orifice. According to Beckman Instruments (http://www.beckman.com/particle/instruments/cell-sizing-and-processing/multisizer-3):

A tube with a small aperture on the wall is immersed into a container in which particles are suspended in a low-concentration electrolyte. Two electrodes, one inside the aperture tube and one outside the tube create a current path through the electrolyte when an electric field is applied. The impedance (effective resistance) between the electrodes is then measured. The aperture therefore creates a sensing zone and particles suspended in the electrolyte can be counted by passing them through the aperture. As a particle passes through the aperture, a volume of electrolyte equivalent to the immersed volume of the particle is displaced from the sensing zone. This causes a short-term change in the impedance across the aperture which can be measured as a voltage or current pulse. The pulse height is proportional to the volume of the sensed particle.

This is a non-destructive method (gently mixing and pumping, with no sonication or blending) and any agglomeration of discrete particles are preserved. Droppo et al. (2002) found that street runoff particulates can be attached into larger clumps and that discrete particle measurement methods resulted in different particle size distributions compared to methods that preserved the actual attachments.

The Coulter Counter Multi-Sizer 3 is most suitable for particles in the range of $\sim 1 \mu \mathrm{m}$ to $200 \mu \mathrm{m}$. Larger particles (especially those $\geq \sim 500 \mu \mathrm{m}$ ) settle to the bottom of the measurement vessel and are not easy to keep suspended and drawn through the analytical aperture. Coulter recommends increasing the viscosity of the analytical solution (such as by using Karo syrup) to keep particles as large as $1200 \mu \mathrm{m}$ suspended. We were never pleased with this option. Normally, we have found only a few sand grains in the bottom of sample bottles, or in the Coulter vessel, when 
the instrument was not recording their presence. We were not concerned due to their few number and minimal effect on sample mass. However, we have modified our methods to now quantify these larger particles, as outlined below.

The Coulter Counter Multi-Sizer 3 is used to measure particle size distributions of solids up to several hundred micrometers. Larger particles (up to several $\mathrm{mm}$ ) are quantified using sieves. During the past several years, we have started to separate the samples into at least three size fractions: $>106 \mu \mathrm{m}, 0.45 \mu \mathrm{m}$ to $106 \mu \mathrm{m}$, and $<0.45 \mu \mathrm{m}$. Generally, we divide the suspended solids fraction at $106 \mu \mathrm{m}$. The intermediate fraction $(0.45 \mu \mathrm{m}$ to $106 \mu \mathrm{m})$ was therefore used in the Coulter Counter analyses, with no possible interference from large particles. The relatively small fraction of particles $>106 \mu \mathrm{m}$ are therefore quantified and added to the size distribution (the $<0.45 \mu \mathrm{m}$ dissolved fraction is reported as TDS, but filtered pollutants are not all ionic as the filtrate contains colloids and chemical complexes; see Morquecho 2005). Figure 8 is a photograph of filtering a sample portion through a $106 \mu \mathrm{m}$ sieve (as the general upper limit of the Coulter Counter, and the upper limit of TSS, and to protect the $140 \mu \mathrm{m}$ aperture in the Coulter Counter from clogging).

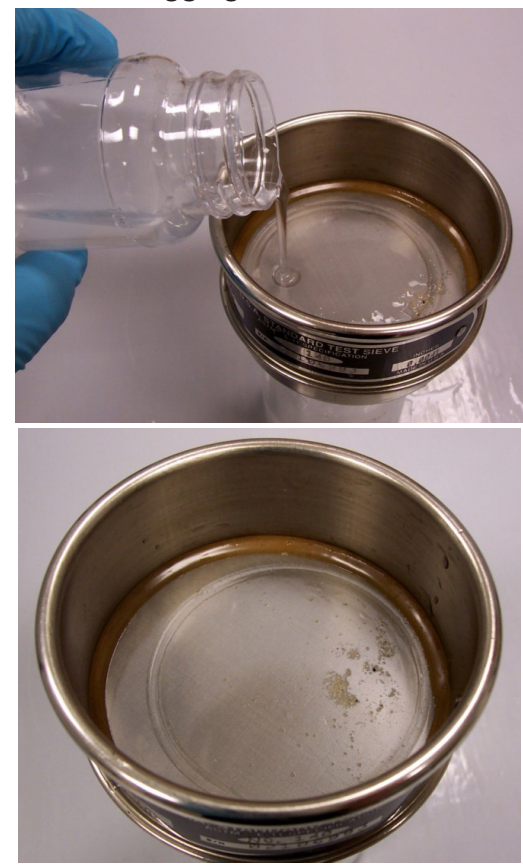

Figure 8 Wet sieving sample with $106 \mu \mathrm{m}$ sieve before Coulter Counter analyses; upper: pre-sieving a sample with $106 \mu \mathrm{m}$ sieve (before use of $140 \mu \mathrm{m}$ aperture tube); lower: large particles (sands) captured in the $106 \mu \mathrm{m}$ sieve.

In order to conduct the particle size analyses, the sample is split using the cone splitter into at least four separate 100 $\mathrm{mL}$ subsamples. One subsample is analyzed for total solids (unfiltered), another sample is analyzed for dissolved solids (after filtering through a glass fiber nominal $2 \mu \mathrm{m}$ filter, replacing the above noted $0.45 \mu \mathrm{m}$ membrane filter), and another sample is analyzed for total solids after passing through a $106 \mu \mathrm{m}$ sieve. The fourth sample is analyzed in the Coulter Counter, after sieving through a $106 \mu \mathrm{m}$ sieve. Most of the time we separate a $\sim 1 \mathrm{~L}$ sample (from the original sampler bottle) into ten subsamples. Besides the $106 \mu \mathrm{m}$ sieve, we add a $246 \mu \mathrm{m}$ sieve for an additional point on the PSD curve for the coarser sizes and conduct duplicates for each fraction. We also analyze the amount of material captured on the coarse screen placed on top of the cone splitter. In all cases, the actual subsample volume for each of these analyses is determined using a graduated cylinder for the water after filtration through the glass fiber $2 \mu \mathrm{m}$ filters, or using short graduated cylinders with the cone splitter to collect each subsample. After volume measurements of the subsamples, clean water (preferably $18 \mathrm{M} \Omega$ analytical grade water) is used to rinse the sample bottle and splitter (adding a small amount of water volume to each subsample, but that does not affect the calculations as it does not contain any particulate or dissolved solids). After pouring the subsamples through any sieves and glass fiber filters, additional clean water is used to rinse the subsample bottles. Before the Coulter Counter is used with the $32 \mu \mathrm{m}$ aperture tube (having a $19 \mu \mathrm{m}$ particle size upper limit), the subsample is presieved using a $20 \mu \mathrm{m}$ sieve to prevent tube clogging, as shown in Figure 9. The sample volume sieved is corrected for dilution by the rinse waters during the PSD calculations.

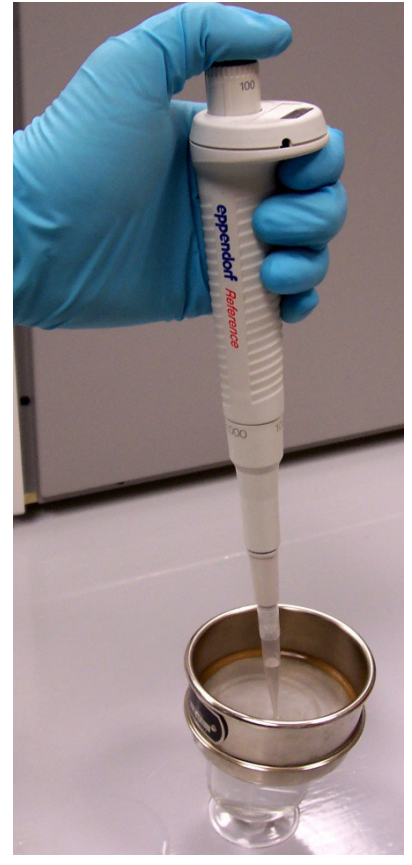

Figure 9 Pre-sieving a sample with $20 \mu \mathrm{m}$ sieve (before use of $32 \mu \mathrm{m}$ aperture tube) directly into the Coulter Counter flask.

\subsection{Comparisons of Alternative TSS and SSC Lab- oratory Methods}

Clark and Siu (2008) compared TSS and SSC analytical methods for stormwater particulates. They confirmed that TSS methods are 
not a suitable method for representing the complete particle size range of stormwater particulates. TSS methods had recoveries of $\sim 75 \%$ for fine sediment sizes, but only $\sim 40 \%$ for the larger particles (up to $500 \mu \mathrm{m}$ ). Gray et al. (2000) also reported differences between TSS and SSC analytical methods for river samples.

Pitt and Cai (2013) and Pitt et al. (2014) compared analytical methods during recent stormwater projects (mostly during several years evaluating the performance of the UpFlo stormwater filter in Tuscaloosa, Alabama and during two years evaluating the performance of green infrastructure components in Kansas City, Missouri). Samples were analyzed for particulate solids using the three methods listed above. In addition, the samples from the upflow filter tests were evaluated comparing membrane $0.45 \mu \mathrm{m}$ filters and glass fiber $2 \mu \mathrm{m}$ filters. Normally, we use several different membrane filter apertures when analyzing the filtered water for varying chemical constituents associated with different sized particles. Interestingly, we found that the $2 \mu \mathrm{m}$ glass fiber filters resulted in larger recoveries of particulates with less variability compared to the $0.45 \mu \mathrm{m}$ membrane filters. The depth filtering of the glass fiber filters are apparently more efficient than the surface filtering of the membrane filters. We have therefore standardized on using the Whatcom glass fiber filters for our TSS and SSC analyses, while using Teflon or polycarbonate membrane filters with specific apertures (such as $20 \mu \mathrm{m}, 10 \mu \mathrm{m}, 5 \mu \mathrm{m}, 3 \mu \mathrm{m}, 1 \mu \mathrm{m}$, $0.45 \mu \mathrm{m}$ and $0.2 \mu \mathrm{m}$ ) for chemical analyses of the particles by size by comparing constituent concentrations in the different filtrates.

Figures 10 through 12 below show the results of the parallel analyses tests from the Kansas City green infrastructure demonstration project (Pitt et al. 2014). These are gutter stormwater samples and were analyzed using the two TSS methods (the EPA shake and pour method and the Standard Method stir and pipette method) and the ASTM SSC method. As noted previously, the Whatcom $2 \mu \mathrm{m}$ glass fiber filters were used for all analyses and approximately $100 \mathrm{~mL}$ samples were used for each parallel test.

Figure 10 plots the TSS concentrations from the shake and pour vs the stir and pipette methods. These results indicated $\sim 22 \%$ average decrease in concentration when using the shake and pour method compared to the stir and pipette method. The paired $t$-test (critical $a=0.05$ ) also indicated a significant difference between the values for the same samples (subsamples obtained from the Dekaport cone splitter) for the different methods. Figure 11 compares the shake and pour TSS results to the USGS SSC results and indicates $~ 14 \%$ average decreases in concentrations with the shake and pour method. The paired $t$-test also indicates a significant difference between the sample pairs. In contrast, Figure 12 compares the stir and pipette TSS concentrations with the SSC concentrations. The average difference was $\sim 7 \%$ and was not shown to be significant (based on the number of paired samples available). Therefore, it may be reasonable to consider the stir and pipette TSS method to result in similar results as the SSC method, while the shake and pour method to result in smaller concentrations with lower recoveries of large particles. Similar results and conclusions were also found when comparing the paired analyses during the upflow filter research project. However, NJDEP (2006) found closer correlations between SSC and shake and pour methods. Therefore, the findings here may only be appropriate for stormwater analyses and their size ranges. Samples not having large particles would likely show closer correlations between all three methods.

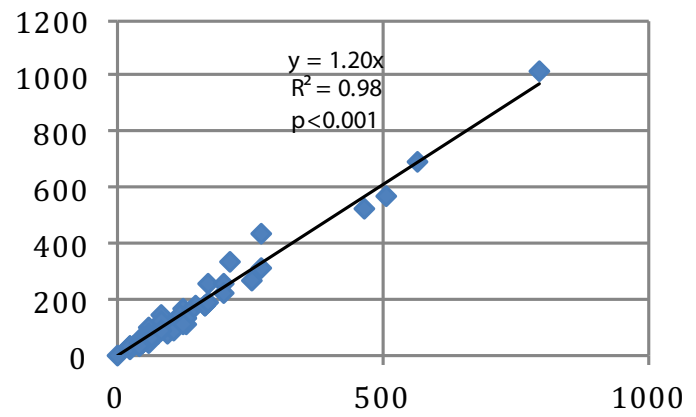

Figure 10 Shake and pour ( $x$-axis) vs stir and pipette ( $y$ axis) TSS results for the same samples, $\mathrm{mg} / \mathrm{L}$.

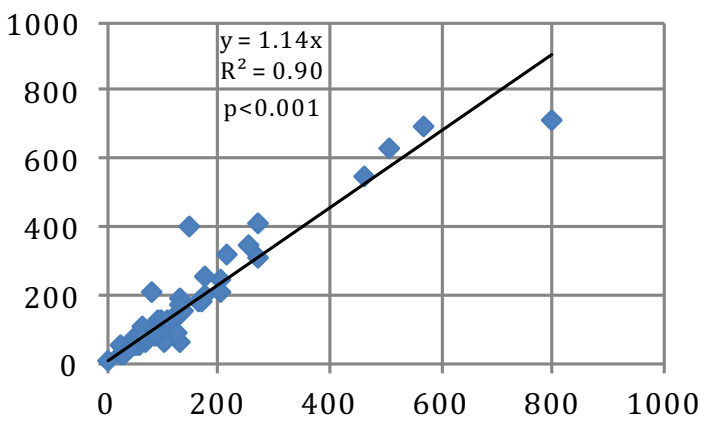

Figure 11 Shake and pour TSS ( $x$-axis) vs SSC ( $y$-axis) analysis results for the same samples, $\mathrm{mg} / \mathrm{L}$.

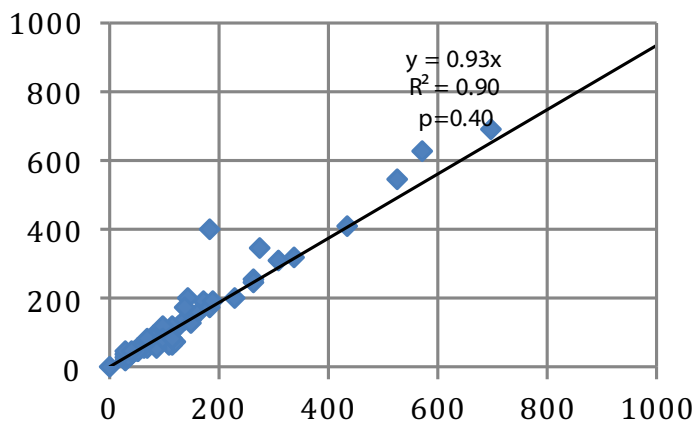

Figure 12 Stir and pipette TSS ( $x$-axis) vs SSC ( $y$-axis) analysis results for the same samples, $\mathrm{mg} / \mathrm{L}$.

\subsection{Particulate Characteristics in Stormwater from a Heavy Industrial Site}

The following discussion summarizes recent results from the monitoring of a heavy industrial site in the southeast United States focusing on particulate characteristics. These data were 
also compared to various rain characteristics in an attempt to explain some of the observed variability.

The 6 ha site is a heavy industrial land use having several buildings (galvanized metal roofs), driveways, loading docks and highly compacted pervious storage areas. Almost all of the roofs and impervious areas are directly connected to drains, except for a few roofs draining directly to compacted soils. Land use characteristics of the site are as shown in Table 3.

Table 3 Detailed land use characterization of test site.

\begin{tabular}{ll}
\hline & Industrial Land Use (ha) \\
\hline Roofs & \\
$\quad$ Roofs Flat - drains to asphalt/concrete & 0.004 \\
Parking/Streets/Sidewalks/Driveways & \\
$\quad$ Paved concrete parking/storage - smooth - directly connected & 0.18 \\
$\quad$ Driveways/loading dock -concrete- directly connected & 1.94 \\
Non-paved Areas & \\
$\quad$ Non-paved storage areas (heavily compacted soils) & 3.29 \\
Open areas (dry pond) & 0.29 \\
Special Areas & \\
$\quad$ Galvanized metal roofs- directly connected & 0.09 \\
Galvanized metal roofs - drains to soil & 0.17 \\
Other galvanized materials- directly connected to drains & 0.08 \\
Total Area (ha) & 6.05 \\
\hline Eppakayala (2015) &
\end{tabular}

Site monitoring used ISCO 4250 area-velocity flow meters with flow sensors to continuously monitor hydrologic conditions, and ISCO 6712 automatic samplers were used to collect flow-weighted composite samples. An ISCO 674 tipping bucket rain gauge was used as a sample trigger to initiate sampling, while the area-velocity sensor in the effluent pipe of the hydrodynamic device was used for sample collection pacing during the events. The automatic samplers were initiated when the rain gauge registered $0.02 \mathrm{in}$. $(0.5 \mathrm{~mm})$ rainfall within $30 \mathrm{~min}$. Subsamples were obtained based on the programmed sample collection pacing. Based on the hydrographs, the time paced sampling was able to represent $80 \%$ to $90 \%$ of the flow for all the monitored events.

In total 14 storm events were monitored from 2013-11 to 2014-06. About $65 \%$ of the events were $<0.5 \mathrm{in}$. $(12.7 \mathrm{~mm}), 27 \%$ were between $0.5 \mathrm{in}$. $(12.7 \mathrm{~mm})$ and $1.5 \mathrm{in}$. (38.1 mm), and $8 \%$ of the events were $>1.5 \mathrm{in}$. (38.1 $\mathrm{mm}$ ).

Composite samples were collected in high density polyethylene bottles. After each targeted storm event, the samples were brought to the UA laboratory as soon as possible and either cooled in a sample refrigerator or immediately processed. Composite samples were split evenly into ten $1 \mathrm{~L}$ bottles using a USGS/Dekaport Teflon cone splitter. Nylon screening material with $1180 \mu \mathrm{m}$ openings was placed on top of the cone splitter to capture larger particles and debris to prevent clogging of the cone splitter. This material was also quantified. SSC and PSD were analyzed at the UA lab. Suspended solids concentrations were analyzed in accordance with the D 3977-97B testing method. The measured total volume of each subsample was used for the SSC and PSD analyses. Particle size distributions were determined in a multi-step procedure of screening (>1 $180 \mu \mathrm{m})$, sieving $(250 \mu \mathrm{m}$ to $1180 \mu \mathrm{m})$ and filtering $(0.45 \mu \mathrm{m}$ to $3 \mu \mathrm{m})$ followed with Coulter Counter analyses ( $3 \mu \mathrm{m}$ to $250 \mu \mathrm{m}$ ).

\section{Results and Discussions}

\subsection{Observed Particulate Characteristics}

The results from the SSC analyses (event mean concentrations collected using flow-weighted composite samplers) are shown in Table 4. Untreated site runoff suspended sediment concentrations ranged between $85 \mathrm{mg} / \mathrm{L}$ to $493 \mathrm{mg} / \mathrm{L}$, with a mean concentration of $253 \mathrm{mg} / \mathrm{L}$. These concentrations of SSC were higher than the industrial runoff concentrations observed in the NSQD (Maestre 2005; Maestre and Pitt 2006), as expected since the data presented in NSQD are a representation of concentrations from outfalls of several light to medium industrial sites throughout the Unites States and do not represent much data from heavy industrial activities. The NSQD data are also reported as TSS and not SSC.

Table 4 Individual and overall mean concentrations for SSC for all monitored events.

\begin{tabular}{|c|c|c|}
\hline Event\# & Rain Depth (in.) & $\mathrm{SSC}$ (mg/L) \\
\hline 1 & 1.42 & 121 \\
\hline 2 & 0.55 & 263 \\
\hline 3 & 0.16 & 266 \\
\hline 4 & 2.52 & 493 \\
\hline 5 & 0.75 & 302 \\
\hline 6 & 0.39 & 234 \\
\hline 7 & 0.47 & 303 \\
\hline 8 & 0.6 & 85 \\
\hline 9 & 0.3 & 282 \\
\hline 10 & 2.36 & 275 \\
\hline 11 & 0.39 & 91 \\
\hline 14 & 0.12 & 234 \\
\hline 15 & 0.95 & 323 \\
\hline 16 & 0.23 & 269 \\
\hline \multicolumn{2}{|c|}{ Mean } & 253 \\
\hline \multicolumn{2}{|c|}{ St. Dev } & 105 \\
\hline \multicolumn{2}{|c|}{$\mathrm{COV}$} & 0.42 \\
\hline \multicolumn{2}{|c|}{ Minimum } & 85 \\
\hline \multicolumn{2}{|c|}{ Maximum } & 493 \\
\hline
\end{tabular}

Note: no samples were collected for events 12 and 13.

The results of particle size distributions for all the 14 analyzed samples are shown in Figure 13. Median particle sizes for all the monitored events ranged between $7.5 \mu \mathrm{m}$ and $45 \mu \mathrm{m}$, with an average median particle size of $21 \mu \mathrm{m}$. These particle size distributions were similar to previous studies (House et al. 1993; Pitt et al. 1995). Almost all (>80\%) of the suspended sediment is distributed in the particle size range $3 \mu \mathrm{m}$ and $120 \mu \mathrm{m}$. 


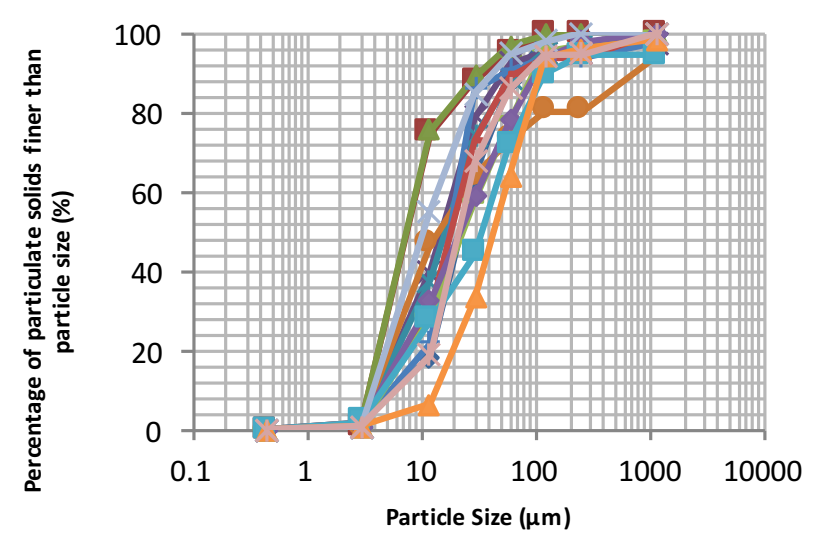

Figure 13 Particle size distributions for all the monitored influent samples.

\subsection{Relationships Among Hydrologic Parameters and Suspended Sediment}

\section{Regression Analyses}

Regression analyses with ANOVA were used to determine associations between variables (independent and a dependent variable) using Minitab (Version 17). No strong significant correlations were observed between site hydrology and SSC. This is likely associated with the heavily compacted soils on the site and their lower erosion potential indicating little relationship between the particulate solids and rain energy. Erosion was not a significant factor and SSC and particulate material on the site varies greatly as site activities and materials stored varies throughout the year, making poor relationships between SSC and rain characteristics. The supply of suspended sediment was limited (and variable) on the site and factors most affecting SSC in the runoff were therefore not related to the rainfall.

There were also poor relationships between the antecedent dry period and the SSC concentrations (no obvious buildup and washoff patterns for the paved storage areas at the site for the short accumulation periods in the southeast).

SSC showed moderate (but significant) positive correlations with average ( $p<0.05, R^{2}=0.40$ ) and peak rain intensities $\left(p<0.05, R^{2}=0.45\right)$ and weak linear correlations (not statistically significant) with rain depth ( $\left.p>0.05, R^{2}=0.18\right)$, runoff depth and antecedent dry period ( $\left.p>0.05, R^{2}=0.22\right)$.

Median particle sizes of the influent particulates apparently decreased with increases in rain depth, rain intensity and antecedent dry period, but without any significant relationships based on the numbers of data observations available.

\section{Multivariate Analyses}

Multivariate analyses were conducted to study more complex relationships between different hydrologic and particulate characteristics than the previous regression analyses. The different analyses performed include Pearson correlation analyses, cluster analyses and principal component analyses. Pearson correlation analyses were performed to determine simple associations between different pairs of parameters, while cluster analyses were performed to identify more complex relationships between the parameters. Principal component analyses were performed to identify groupings of parameters with similar characteristics to explain the variability in the data. The statistical software package XLSTAT 2015 supplement to Excel was used to conduct most of these analyses.

Pearson correlation analyses were performed to investigate relationships between different hydrologic characteristics and SSC and PSD. Parameters examined were rain and runoff depths, average and peak rain intensities, inter-event time, median suspended sediment particle size, and SSC. Cluster analyses and principal component analyses were also used to evaluate more complex interactions between the rain and the SSC and median particle size characteristics. The median particle sizes were negatively correlated (but not statistically significant) with hydrologic and water quality parameters, indicating smaller median particle sizes as the rain depth and intensities increased, an unexpected result as increasing rain intensities and flow rates are associated with greater flow energy and should be more capable of eroding and transporting larger particles.

Full $2^{2}$ factorial analyses were performed on SSC and median particle size to examine the effects of rain depth and peak rain intensity, and their interactions on particulate characteristics. A full factorial analysis (Box et al. 1978) is a tool used for understanding the effect of two or more independent variables on a dependent variable. The factorial design identifies the effects of individual variables and their interaction on the dependent variable of interest (SSC and median particle size). The effects of different variables are calculated using a table of contrasts, with the averages of the differences between the sums of the pollutant concentrations (or any dependent variable of interest) when the factor is at its maximum value and at its minimum value. Probability plots of the calculated effects for individual plots and outliers (abnormal points) indicate the most important factors and different factor associations on the dependent variable of interest. High values for rain depth were 0.75 in. to 2.52 in. $(19 \mathrm{~mm}$ to $64 \mathrm{~mm}$ ), while low values for rain depth were $0.1 \mathrm{in}$. to $0.47 \mathrm{in}$. ( $2.5 \mathrm{~mm}$ to $12 \mathrm{~mm}$ ). High values for peak $5 \mathrm{~min}$ rain intensity were $0.96 \mathrm{in} . / \mathrm{h}$ to $3.4 \mathrm{in} . / \mathrm{h}(24 \mathrm{~mm} / \mathrm{h}$ to $86 \mathrm{~mm} / \mathrm{h})$ and low rain intensity values were from $0.12 \mathrm{in} . / \mathrm{h}$ to $0.72 \mathrm{in} . / \mathrm{h}(3.0 \mathrm{~mm} / \mathrm{h}$ to $18 \mathrm{~mm} / \mathrm{h})$. The data were sorted into the four categories corresponding to the rain depth and intensity codes, and the factors for each main factor and interactions were calculated. The significant factors were identified by probability distributions of the results by observing which were not associated with the normal distribution of the calculated values.

Probabilities of the effects of the factors on SSC and median particle size were calculated. Rain depth and peak rain intensity, or their interaction, did not show any significant effects 
on the SSC concentrations (based on the number of available observations), while their interactions have an apparent effect on the median particle size.

It would require substantial amounts of data to identify significant relationships between SSC, PSD and site and hydrological parameters. Large amounts of data are available for particulate solids from many monitoring projects that focused specifically on accumulation rates (see summary papers prepared for the $\mathrm{CHI}$ conference series, for example Pitt et al. 2005). However, few data sets are sufficient to explain the variability in PSD. Continued monitoring work by the USGS and WI DNR are investigating these relationships for Wisconsin conditions.

\subsection{Summary of Particle Size Distribution Data}

Particle size distribution data were collected and compared from a number of different stormwater studies. The PSD data were from source area sheetflows reflecting stormwater quality from different surfaces and areas (such as runoff from roofs, parking lots and storage areas, and landscaped areas). Data representing both TSS (shake and pour) and TSS (stir and pipette) plus SSC subsampling methods were available. The samples were collected either using manual grab sampling techniques from the sheetflows, or using automatic samplers at well-mixed sampling locations. The following briefly describes the major sources of these data, followed by summary plots of the PSDs for different categories.

A total of 75 grab stormwater sheetflow samples collected during research examining the treatability of stormwater and the development of the multi-chambered treatment train, MCTT, were evaluated for particle sizes (Pitt et al. 1999). These samples were obtained from sheetflows during rains using a vacuum sample bottle and Teflon tube and represented the complete size distribution. The samples were analyzed using an early model laser particle counter. However, it was apparent that this instrument did not detect particles $>\sim 75 \mu \mathrm{m}$, close to the upper limit of particles for TSS. Therefore these data should only be applied to a modeling situation where the particulate solids calibration and verification relied on TSS data, as using PSD data from SSC samples with TSS calibrations would artificially increase the importance of the larger particles, resulting in increased (in error) particulate capture calculations.

Particle size distributions were also obtained from several monitoring locations in the Madison, Wisconsin area collected by the USGS (Selbig 2014). These data are unique in that the samples were collected using a new sampler intake that more accurately collects water from the complete depth of flow during a rain event, minimizing stratification issues associated with single point sampling, and represent SSC conditions. These sample particle size distributions were determined using sieving methods for the large particles and a Coulter Counter for the smaller sized particles. These distributions should not be used with a model that has been calibrated using TSS shake and pour data.
PSD data from other stormwater research projects were also included in this summary (Morquecho 2005; Pitt and Cai 2013; Pitt et al. 2014; Eppakayala 2015; Selbig et al. 2016).

Figures 14 through 18 sort these particle size distributions into the following sets of source areas: roof runoff, runoff from paved urban areas, runoff from non-paved urban areas, and runoff from landscaped and open space areas. Only the SSC and TSS stir and pipette PSDs are shown. These plots also include an averaged PSD plot. These groupings and resulting plot comparisons further support that TSS stir and pipette method is close to the SSC method. Similar TSS shake and pour PSDs are missing large particles.

It should be emphasized that some stormwater managers and regulatory agencies specifically specify TSS goals (and not SSC) due to historical regulatory precedent with other wastewaters. Stormwater modeling in this case needs to rely on TSS shake and pour data and associated TSS particle size distributions that do not include the larger particles.

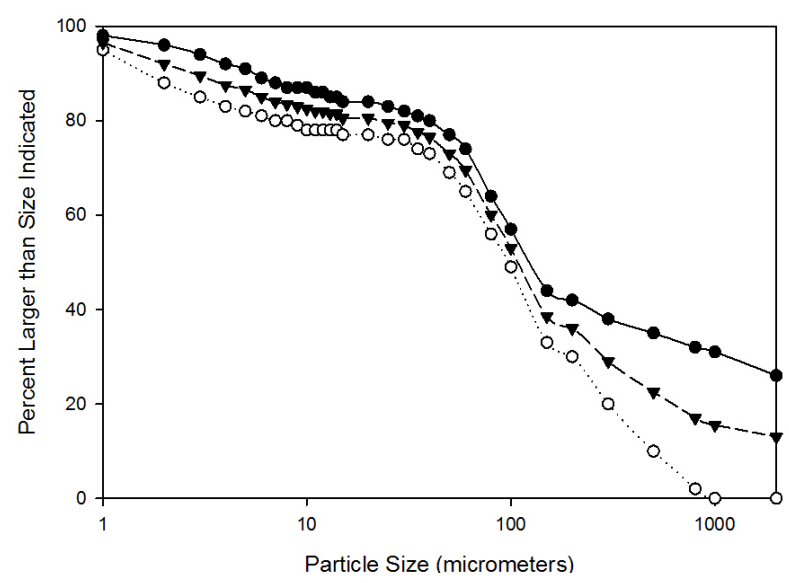

Figure 14 Roof runoff particle size distributions (TSS stir and pipette plus SSC).

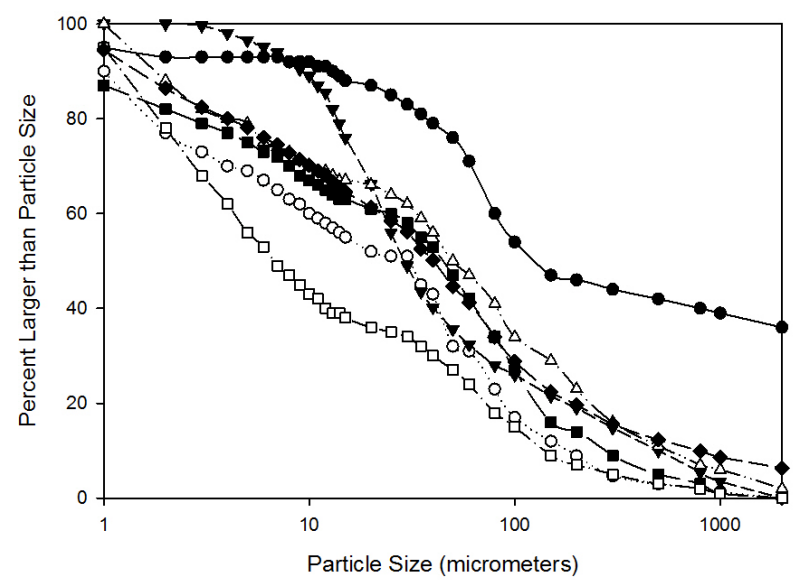

Figure 15 Paved parking, storage, loading dock, vehicle service area and street runoff particle size distributions (TSS stir and pipette plus SSC). 


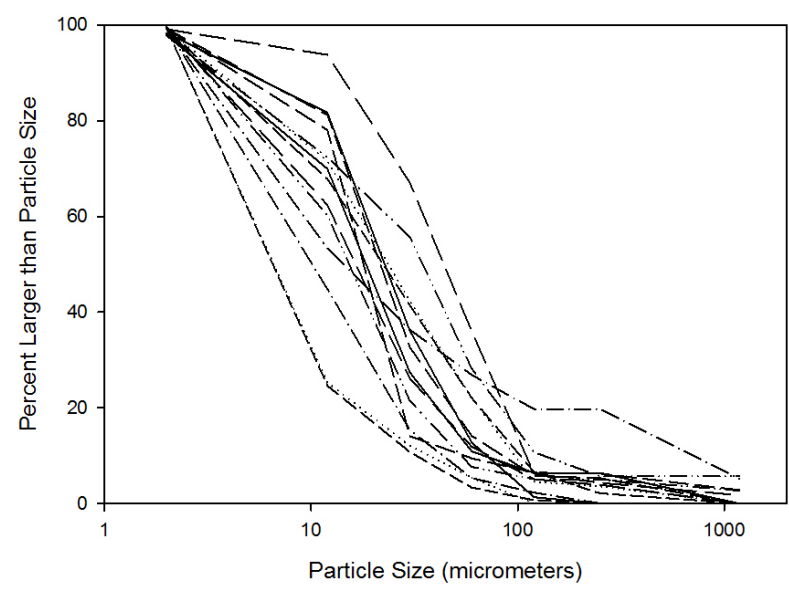

Figure 16 Non-paved parking and storage area runoff particle size distributions (TSS stir and pipette plus SSC).

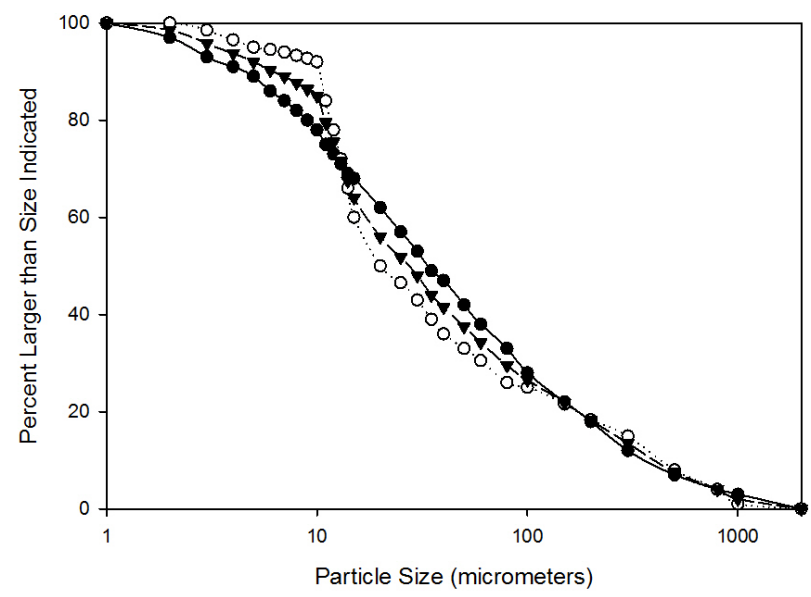

Figure 17 Landscaped, open space and construction site runoff particle size distributions (TSS stir and pipette plus SSC).

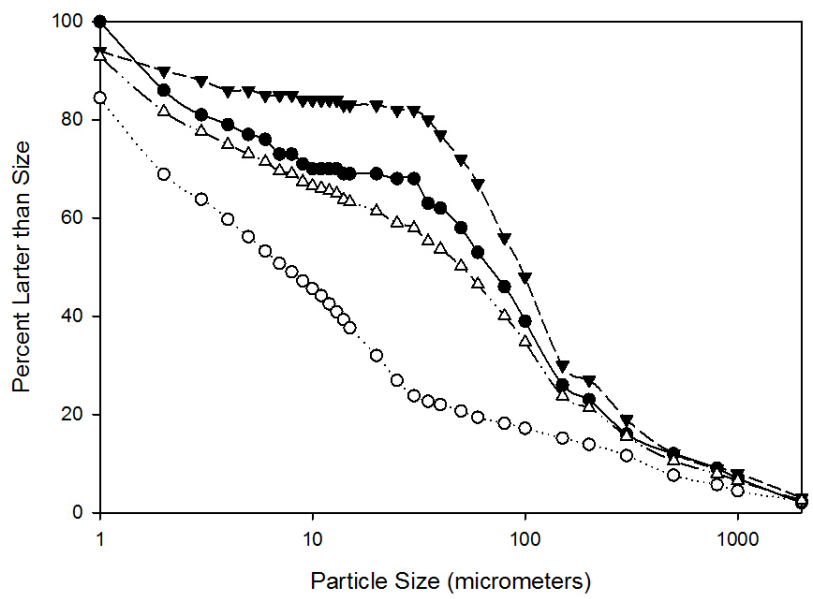

Figure 18 Outfall discharges particle size distributions (TSS stir and pipette plus SSC).
Table 5 is a summary showing the median particle sizes for each of these categories (along with outfall sample data for events during the sheetflow sampling periods for comparison). The coefficients of variation are also shown for each category, indicating relatively narrow ranges for the median particle sizes, with the outfall medians having a much greater variation. Except for the roof runoff and the outfall samples, the median sizes for the TSS and SSC prepared samples are similar. Table 5 also shows the typical 90th percentile particle sizes (10\% of particles, by mass, are larger than these sizes). The TSS PSD distributions determined by shake and pour sample splitting methods have much narrower ranges with fewer large particles compared to the SSC PSD distributions for the same category.

Table 5 Summary of source area median particle sizes.

\begin{tabular}{lcccccc}
\hline & \multicolumn{3}{c}{ Shake and Pour TSS } & \multicolumn{3}{c}{ Stir and Pipette and SSC } \\
& $\begin{array}{c}\text { median size } \\
(\mu \mathrm{m})\end{array}$ & COV & $\begin{array}{c}\text { 90th percentile } \\
\text { size }(\mu \mathrm{m})\end{array}$ & $\begin{array}{c}\text { median size } \\
(\mu \mathrm{m})\end{array}$ & CoV & $\begin{array}{c}\text { 90th percentile } \\
\text { size }(\mu \mathrm{m})\end{array}$ \\
\hline roofs & 21 & 0.3 & 30 & 110 & 0.2 & 1000 \\
paved areas & 32 & 0.2 & 60 & 33 & 0.6 & 500 \\
unpaved areas & 39 & 0.3 & 50 & 20 & 0.5 & 70 \\
landscaped areas & 35 & 0.4 & 40 & 26 & 0.3 & 300 \\
outfalls & 26 & 0.9 & $\mathrm{n} / \mathrm{a}$ & 61 & 0.8 & 500 \\
\hline
\end{tabular}

\subsection{Particulate Movement in Drainage Systems}

Table 6 presents settling conditions for particulates moving in a $3 \mathrm{ft}(90 \mathrm{~cm})$ diameter pipe, and for flow depths ranging from $10 \%$ to $100 \%$ of the pipe diameter. This table shows the distances the particles would travel before they would settle to the bottom of the pipe, if starting from the surface of the flow, using Manning's equation to calculate the stormwater velocity, and the combination of Stokes's and Newton's laws for settling rates. A particle settling to the pipe bottom doesn't imply that the particles would be permanently trapped as sediment, but the particles may move (relatively slowly) as part of a mobile bedload during periods of flow, but would become compacted after the flow ceases. The flow distances required for settling of the small particles $<100 \mu \mathrm{m}$ (not shown on this table) are very long and these small particles would generally remain suspended. Some of the $100 \mu \mathrm{m}$ particle flow conditions are shown to result in relatively short settling distances, while most of the $1000 \mu \mathrm{m}$ (and larger) particles would almost certainly settle to the pipe bottom before reaching the outfall.

Table 6 Settling distance (ft) for particles flowing in pipes having various diameters and slopes, $n=0.013(3 \mathrm{ft}$, $0.9 \mathrm{~m}$, example diameter).

\begin{tabular}{lcccccc}
\hline & \multicolumn{2}{c}{$\begin{array}{c}100 \mu \mathrm{m} \text { particles } \\
\text { (2.5 specific gravity) }\end{array}$} & \multicolumn{2}{c}{$\begin{array}{c}1000 \mu \mathrm{m} \text { particles } \\
\text { (2.5 specific gravity) }\end{array}$} \\
$\begin{array}{l}\text { flow depth/pipe } \\
\text { diameter ratio }\end{array}$ & $\begin{array}{c}\text { 0.001 slope } \\
0.01 \text { slope }\end{array}$ & 0.02 slope & 0.001 slope & 0.01 slope & 0.02 slope \\
\hline 0.1 & 12 & 39 & 55 & 0.5 & 1.7 & 2.5 \\
0.3 & 71 & 230 & 320 & 3.2 & 10 & 14 \\
0.5 & 150 & 480 & 680 & 6.9 & 22 & 31 \\
0.8 & 280 & 880 & 1200 & 13 & 40 & 56 \\
1 & 310 & 960 & 1400 & 14 & 43 & 61 \\
\hline
\end{tabular}


Shear stress calculations show that for the smallest slopes, almost all settled particles would likely remain and not be scoured, while almost all unconsolidated sediments would be scoured for pipes $>1 \%$ slope. Pipe conditions resulting in at least $3 \mathrm{ft} / \mathrm{s}(0.9 \mathrm{~m} / \mathrm{s})$ stormwater velocities (a typical design objective) would have shear stresses of at least $0.08 \mathrm{lb} / \mathrm{ft}^{2}\left(0.003 \mathrm{~kg} / \mathrm{m}^{2}\right)$. This shear stress would likely cause scour of particles up to $2000 \mu \mathrm{m}$ in size for water having a low content of fine sediment. If the water had a high content of fine sediment (likely for stormwater), the maximum particles likely to be scoured from the sediment may be only $\sim 100 \mu \mathrm{m}$ in size. If the sediment was somewhat consolidated (as expected to occur during dry periods between runoff events), then the necessary shear stress to cause sediment scour would be substantially greater. With compacted sediment, the shear stress would have to be greater than about $0.3 \mathrm{lb} / \mathrm{ft}^{2}$ $\left(0.01 \mathrm{~kg} / \mathrm{m}^{2}\right)$ to affect particles larger than clays. This shear stress may only occur for large and full-flowing pipes having $\geq 2 \%$ slopes (with about $7 \mathrm{ft} / \mathrm{s}$, or $2 \mathrm{~m} / \mathrm{s}$, velocities).

\section{Conclusions}

Particle size information of stormwater particulates is needed for effective modelling of most stormwater pollutants, especially considering their movement from source areas, through available stormwater controls and the drainage system, to the outfall and receiving waters. The ultimate fate of stormwater particulates is also highly dependent on their particle sizes (and other characteristics). Both sample collection and sample processing methods can affect the measured particle size distributions and the particulate solids concentrations. Care needs to be taken to ensure that the data correctly reflect the monitoring objectives.

Sample collection methods may affect the particle size distributions (and particulate solids concentrations) of the sample. Automatic samplers with intakes on the bottom of a pipe can preferentially collect more of the bedload-associated larger particles than represented in well mixed samples. Samples should be collected using depth-integrated sampling, or from well mixed (such as cascading) flows to best represent the particle size distribution in the flowing water.

Much of the older stormwater particulate concentration data are expressed as total suspended solids (TSS) reflecting how the samples are processed. Unfortunately, TSS data commonly do not include the larger particles in the stormwater. Current emphasis focuses on sample collection and processing that preserves the large particle information by using the suspended sediment concentration (SSC) sampling processing methods. Data from the two TSS methods and SSC method may differ in important ways affecting modelling and analyses. As shown in this paper, TSS prepared by stir and pipette methods provide similar information as SSC methods, while TSS prepared by shake and pour methods usually do not include the larger particles.

If modeling or other analyses focus on TSS measurements (as some stormwater regulations), then applying SSC data can be misleading by including additional large particles in the distribution that may not be effectively transported to the outfalls and receiving waters. This would result in overpredictions of removal performance of stormwater controls. On the other hand, stormwater models that offer complete particulate routing from source areas to the discharge location by incorporating deposition and scour in the collection system, require complete particle size distribution information, as reflected by SSC data.

The largest particles found in stormwater sheetflows from source areas are preferentially deposited along the flow path and drainage system, with a modification of the PSD at the outfall location. There are therefore few appreciable differences in the outfall PSD for SSC and TSS samples because there are relatively few of the larger particles that distinguish the two sets of sample types (>75 $\mu \mathrm{m}$ for example). Therefore, for outfall analyses, it makes little difference if the outfall PSD is a TSS or SSC based sample. An exception would be if the drainage system had very short conveyance distances, such as roads adjacent to receiving waters. However, when calculating source area stormwater controls, the sheetflows likely have many more large particles that would tend to overestimate the benefits of the discharged stormwater at the outfall. Also, when modelling stormwater particulate behaviour in urban areas, it is important that the appropriate PSD is associated with the TSS or SSC calibrated data.

\section{Acknowledgments}

Much of the research reported in this paper was conducted by graduate students (listed as co-authors) as part of their Ph.D. and MSCE research in the Department of Civil, Construction, and Environmental Engineering at the University of Alabama. The funding for the research was provided by several industrial and federal agencies, which is gratefully acknowledged. The thoughtful comments by the manuscript reviewers are also gratefully acknowledged.

\section{References}

Andral, M. C., S. Roger, M. Montréjaud-Vignoles and L. Herremans. 1999. "Particle Size Distribution and Hydrodynamic Characteristics of Solid Matter Carried by Runoff from Motorways." Water Environment Research 71 (4): 398-407.

ASTM. 2014. Standard Guide for Sampling Fluvial Sediment in Motion, Standard D4411. Book of Standards Volume 11.02. West Conshohocken, PA: ASTM. https://doi.org/10.1520/D4411-03R14E01.

Box, G. E., W. G. Hunter and J. S. Hunter. 1978. Statistics for Experimenters. New York: John Wiley and Sons.

Burton, G. A. Jr. and R. E. Pitt. 2002. Stormwater Effects Handbook: A Tool Box for Watershed Managers, Scientists, and Engineers. Boca Raton, FL: CRC Press. ISBN 0-87371-924-7.

Clark, S. E. and C. Y. S. Siu. 2008. "Measuring Solids Concentration in Stormwater Runoff: Comparison of Analytical Methods." Environmental Science \& Technology 42:511-6. 
Droppo, I. G., K. N. Irvine and C. Jaskot. 2002. “Flocculation/Aggregation of Cohesive Sediments in the Urban Continuum: Implications for Stormwater Management." Environmental Technology 23:27-41.

Eppakayala, V. K. 2015. Performance Evaluation of Stormwater Treatment Controls at an Industrial Site. Tuscaloosa, AL: University of Alabama. Ph.D. dissertation, Department of Civil, Construction, and Environmental Engineering.

Gray, J. R., G. D. Glysson, L. M. Turcious and G. E. Schwarz. 2000. Comparability of Suspended-Sediment Concentration and Total Suspended Solids Data. Reston, VA: USGS. Water-Resources Investigations Report 00-4191. http://water.usgs.gov/osw/pubs/WRIR00-4191.pdf.

House, L. B., R. B. Waschbusch and P. E. Hughes. 1993. Water Quality of an Urban Wet Detention Pond in Madison, Wisconsin, 1987-88. Reston, VA: U.S. Geological Survey. USGS OpenFile Report 93-172. https://pubs.usgs.gov/of/1993/0172/report.pdf.

Kim, J.-Y. and J. Sansalone. 2008. “Particulate Matter Particle Size Distributions Transported in Urban Runoff." In World Environmental and Water Resources Congress 2008 Proceedings, 1-10. Reston, VA: ASCE (American Society of Civil Engineers). https://doi.org/10.1061/40976(316)46.

Li, Y., S. L. Lau, M. Kayhanian and M. K. Stenstrom. 2006. “Dynamic Characteristics of Particle Size Distribution in Highway Runoff: Implications for Settling Tank Design." Journal of Environmental Engineering 132 (8): 852-61.

Maestre, A. 2005. Stormwater Characteristics as Described in the National Stormwater Quality Database. Tuscaloosa, AL: University of Alabama. Ph.D. dissertation, Department of Civil, Construction, and Environmental Engineering.

Maestre, A. and R. E. Pitt. 2006. "Identification of Significant Factors Affecting Stormwater Quality Using the National Stormwater Quality Database." Journal of Water Management Modeling R225-13. https://doi.org/10.14796/JWMM.R225-13.

Morquecho, R. E. 2005. Pollutant Associations with Particulates in Stormwater. Tuscaloosa, AL: University of Alabama. Ph.D. dissertation, Department of Civil, Construction, and Environmental Engineering.

NJDEP (New Jersey Department of Environmental Protection, Division of Science, Research, and Technology). 2006. Correlation of Total Suspended Solids (TSS) and Suspended Sediment Concentration (SSC) Test Methods. Trenton, NJ: New Jersey Department of Environmental Protection, Division of Science, Research, and Technology. Contract No. SR05-005. http://www.state.nj.us/dep/dsr/soils/tss\%20vs\%20ssc\%20 test\%20methods.pdf

Pitt, R. E. and Y. Cai. 2013. Full-Scale Up-Flo Filter Field Performance Verification Tests. Hydrolnternational, Portland, ME. 2013. http://unix.eng.ua.edu/ rpitt/Publications/5_Stormwater_Treatment/Treatment_trains_and_sizing_controls/ Upflow_Filter/UpFlo\%20Filter\%20Final\%20Performance\%20Report.pdf

Pitt, R. E., R. Field, M. Lalor and M. Brown. 1995. “Urban Stormwater Toxic Pollutants: Assessment, Sources, and Treatability." Water Environment Research 67 (3): 260-75.

Pitt, R. E., B. Robertson, P. Barron, A. Ayyoubi and S. Clark. 1999. Stormwater Treatment at Critical Areas: The Multi-Chambered Treatment Train (MCTT). Cincinnati, OH: U.S. Environmental Protection Agency, Wet Weather Flow Management Program, National Risk Management Research Laboratory. EPA/600/R-99/017.

Pitt, R. E., L. Talebi, D. O'Bannon, D. Bambic and J. Wright. 2014. "Modeling of Green Infrastructure Components and Large Scale Test and Control Watersheds at Kansas City, MO." Prepared for USEPA and Tetra Tech, January, 2014. http://rpitt.eng.ua.edu/Publications/8_Stormwater_ Management_and_Modeling/WinSLAMM_modeling_examples/WinSLAMM\%20KC\%20Aug\%203\%202011_EPA\%20 formatted.pdf.

Pitt, R. E., D. Williamson, J. Voorhees and S. Clark. 2005. “Review of Historical Street Dust and Dirt Accumulation and Washoff Data." Journal of Water Management Modeling 14:R223-12. https://doi.org/10.14796/JWMM.R223-12.

Selbig, W. R. 2014. “Characterizing the Distribution of Particles in Urban Stormwater: Advancements Through Improved Sampling Technology." Urban Water Journal 12 (2): 111-9.

Selbig, W., M. N. Fienen, J. A. Horwatich and R. T. Bannerman. 2016. "The Effect of Particle Size Distribution on the Design of Urban Stormwater Control Measures." Water 8 (1): 17. https://doi.org/10.3390/w8010017. 